\title{
Resilience in Arts and Cultural Nonprofit Organizations: An Analysis of the Covid-19 Crisis in France
}

\author{
Guillaume Plaisance ${ }^{1}$ (D)
}

Accepted: 4 November 2021/Published online: 17 January 2022

(c) International Society for Third-Sector Research 2021

\begin{abstract}
This article seeks to analyze the resilience of arts and cultural nonprofit organizations in France during the Covid-19 crisis. A broad survey and multiple logistic regressions highlight the resources availability, the crisis impact, the NPOs' needs and the reforms they conducted during the first French lockdown. This study shows that the resilience of these NPOs must be differentiated between activity continuity and organizational persistence. Resilience in culture and the arts is specific, based on reforms, and requires special support from partners.
\end{abstract}

Keywords Covid-19 $\cdot$ Resilience $\cdot$ Nonprofit

organizations · Community · Viability

\section{Introduction}

"With only a few months of cash on hand, numerous organizations and individuals in arts and culture have lived perpetually on the brink of extinction" (Betzler et al., 2020, p. 796). Arts and cultural nonprofit organizations (NPOs) are therefore experiencing an organizational crisis in addition to the health, economic and social crisis that affects all sectors and almost all countries.

A crisis is defined as "a low-probability, high-impact event that threatens the viability of the organization and is characterized by ambiguity of cause, effect, and means of resolution, as well as by a belief that decisions must be made swiftly" (Pearson \& Clair, 1998, p. 3). The

Guillaume Plaisance

guillaume.plaisance@u-bordeaux.fr

1 Research Institute in Management Science, Bordeaux University, Bordeaux, France conversion of this global crisis into an organizational crisis can be explained in particular by the decrease in funding and partnerships (as explained by Mano, 2010), but also because the cultural and arts institutions have remained closed for many months.

NPOs in general have been studied in the context of the pandemic. Their activity has collapsed (Kim \& Mason, 2020), especially in the sports, leisure, arts and cultural sectors (Plaisance, 2021a). Their governance has sometimes been interrupted despite its crucial role in crises (McMullin \& Raggo, 2020). Three issues in particular stand out.

First, NPOs have relied on human capital to sustain themselves during the crisis (Akingbola, 2020), but working and volunteering conditions have deteriorated. Second, the economic and financial fragility of the nonprofit sector has worsened due to the loss of stable resources (FinchumMason et al., 2020; Johnson et al., 2020; Kim \& Mason, 2020). Third, NPOs have seen their partnerships and relationships with their stakeholders erode, while they are particularly dependent on them (Plaisance, 2021b).

As pointed out by Betzler et al. (2020), arts and cultural NPOs are on the verge of bankruptcy and collapse. Strengthening their capabilities to survive is therefore essential. In the context of a pandemic crisis, the concept of resilience appears even more crucial (Bhaskara \& Filimonau, 2021; Lloyd-Smith, 2020). Studies have already shown that the resilience of the community around NPOs allows them to better weather the crisis (Paarlberg et al., 2020), but they remain anchored in a financial vision (Chen, 2021; Green et al., 2021; Kober \& Thambar, 2021).

NPOs are particularly concerned with the concept of resilience, perhaps even more so than corporations in that their activities have immediate social and societal impacts on communities (Valero et al., 2015). However, research 
has remained discreet on this concept applied in NPOs (Witmer \& Mellinger, 2016).

More globally, the concept is gaining importance in recent years: its dimensions and definitions are growing (e.g., Al-Ayed, 2019; Darkow, 2019; Littlewood \& Holt, 2018; Sawalha, 2015) and needed reviews (e.g., Hillmann \& Guenther, 2021; Linnenluecke, 2017; Ma et al., 2018) and reconceptualization (e.g., Chen et al., 2021; Ma et al., 2018)

The objective of this research is therefore to determine the support that arts and cultural NPOs need to bounce back and the concept of resilience is the selected analysis filter. The study focuses on the French case because NPOs are still little analyzed even if the effects of the Covid-19 crisis are gradually studied in France. The lockdown imposed in the country in the spring of 2020 was particularly severe and plunged the arts and culture NPOs into a very severe crisis. Another lockdown was conducted in the autumn of 2020 and a third lockdown was decided during the spring of 2021. As a result, NPOs operated at a slower pace and the arts and cultural sector was only able to welcome the public under strict sanitary protocol for two months. The French arts and cultural sector is one of the most affected in Europe, due to the restrictions put in place (curfew, gauges for gatherings, etc.), but is also the most financially supported (Bourlès \& Nicolas, 2021).

After reviewing the definitions and dimensions of the concept of resilience, its application to NPOs is reminded. This analytical framework then structures the study of data from a large survey of French NPOs after the end of the first lockdown. The results then make it possible to highlight the willingness of NPOs to bounce back despite the current context, as well as the needs expressed and the conducted reforms.

\section{Organizational Resilience: Definition and Application in NPOs}

Resilience is a concept that originally emerged from the material sciences and has gradually spread to the sciences in general. In Latin, resilience means to rebound (Sabatino, 2016). The notion of equilibrium is therefore central: resilience is the capacity to return to the original equilibrium after having suffered a disturbance (Bhamra et al., 2011). In this equilibrium are also the "structure, identity and functions" of the disturbed system, which must be maintained despite the perturbation (Sabatino, 2016).

Resilience is often equated with an organization's ability to survive a crisis (Darkow, 2019; Kimberlin et al., 2011; Orth \& Schuldis, 2021). Another vision has also developed in the literature: it makes resilience a complete process and not only an output or outcome. For example, Burnard and
Bhamra (2011) identify resilience as a three-stage process, beginning with the ability to respond to an issue, continuing with the abilities to adapt and adjust and ending with organizational learning (also highlighted by Moran, 2016; Valero et al., 2015; Witmer \& Mellinger, 2016).

Resilience is notably challenged by systemic events, such as crises, external shocks or the intensity of competition, but also by less global events such as scandals or management errors (Fyffe, 2014; Vogus \& Sutcliffe, 2007). In short, it is a matter of responding and adapting to the contingencies and requirements imposed by the environment (Fyffe, 2014; Witmer \& Mellinger, 2016). Resilience can thus be defined as "the ability to recover from setbacks, adapt well to change, and keep going in the face of adversity" (Ovans, 2015).

The literature has sought to understand the determinants of resilience in order to improve it (Duchek, 2020). Lengnick-Hall, Beck and Lengnick-Hall (2011) noted that organizational resilience relies in particular on three types of capabilities: cognitive, behavioral and contextual. Beyond material or managerial factors, the subjectivity and vision of leaders play a major role in building resilience (Visser, 2020). For instance, Horne and Orr (1997) listed behaviors that support organizational resilience: community, competence, commitment, communication, coordination and consideration. As Duchek $(2014,2020)$ points out, the literature is divided into three fields: resilience as a rebound ("coping"), as reforms conducted during and after the rebound ("adaptation") and as a preparation ("anticipation"). This study is more in line with the second perspective.

The literature has little studied resilience in NPOs and in the arts and culture sector. In particular, Pratt (2015) looked at cultural organizations and found that the holistic view of resilience is the one that should be favored by this sector. This systemic view, as opposed to the atomistic one, leads the author to see resilience as flexibility and openness: "resilient here is not about growth and survival at any cost, but changing the nature of the objective and working with resource" (Pratt, 2015, p. 62). Pratt therefore opposes prosperity, to be favored, to growth: for him, the resilience of cultural organizations relies on their ability to evolve and adapt, especially with the available resources. Their resilience is also an issue of local community, which retains the legacy of activities, and is therefore based on a triptych vision: economic, social and cultural resilience.

NPOs in general were also studied. Fyffe (2014) reports the following typology. The "low-level resilience" is based on organizational flexibility and adaptability. This dimension of resilience focuses on the ability to maintain and adapt the NPO's activity (and in particular its identity) (also indicated by Valero et al., 2015) as well as its links with the environment, in particular with key stakeholders 
(Liu \& Yin, 2020). The "modest / mid-level resilience" relies on recovery and restoration. In short, NPOs need to analyze their resources to understand the extent to which they can recover. Finally, the "high-level resilience" is associated with thriving and transformation. To do this, NPOs have identified the needs to revive themselves and then ensure their prosperity but also carry out the necessary reforms.

However, this theoretical framework seems difficult to apply to the Covid-19 case. On the one hand, Fyffe's view incorporates all time horizons, whereas the short-term reaction of NPOs is examined here. On the other hand, this conception deals with risks that are less global and less impactful than a global health shock. Fyffe's typology gives content to the concept of resilience to be studied but needs to be completed.

Kimberlin et al. (2011) have constructed another theoretical framework for NPOs in which internal factors (such as evaluation and infrastructure), leadership (related to the team, governance or more global) and external factors (the community, political actors or financial actors) improve both the resilience and growth of NPOs. In short, NPOs "improve their resilience in response to a disaster by interacting with core organizations and accessing their resources" (Kim et al., 2020, p. 1320).

A few studies address the concept of resilience in Covid19 times in NPOs. Searing et al., (2021, p. 3) define it as "the ability to withstand adverse conditions while still delivering services". The authors thus insist on the balance to be found between decisions in favor of "organizational persistence" and in favor of activity continuity. In other words, studying the resilience of NPOs during the Covid19 crisis requires, as a first step, understanding the decisions made by the organizations.

In order to study the resilience of NPOs, this study is based on the last four references cited. First, even if Fyffe's vision of resilience is not directly applicable to the Covid19 crisis, the themes of its typology are included. Second, Kim et al. (2020) emphasize that access to resources and relationships are key determinants of NPOs' situations. Kimberlin et al. (2011) join Searing et al. (2021) in linking the external issues with internal evaluation (especially of needs) and the decisions to be made. Searing et al. (2021) indeed insist on the potential needed reforms to both continue to operate and to persist after the crisis.

Figure 1 illustrates the analytical framework chosen in seeking to examine the antecedents of decisions made to protect NPO resilience (following Rodríguez-Sánchez et al., 2021). Based on the crisis impact on the activity and on the relations with the stakeholders as well as on the resources available to the NPOs, the study analyzes the organizations' needs. The reforms carried out are then studied.
Organizational resilience is therefore present at every stage of the proposed framework. The research questions arising from this vision are therefore:

RQ1: How resilient have French arts and cultural

NPOs been in the face of the Covid-19 crisis?

RQ2: What is the type of support needed by NPOs ?

The research questions emerge from the convergence of the literature reviewed and the initial objective of this article. RQ1 is based on the theoretical frameworks previously discussed, and RQ2 is more about understanding the support needed by the arts and cultural sector. In other words, it is to determine how stakeholders can help NPOs to accomplish their reforms and meet their needs. The determinants of the needs expressed by NPOs and of the reforms are therefore particularly studied and will be linked to NPOs' stakeholders.

\section{Data and Methods}

The sanitary measures put in place in France during the first wave of the Covid-19 epidemic were particularly strict. A two-month lockdown was decided, leading to the closure of all public places, a generalization of teleworking and a control by attestation of honor of the exits. Most NPOs were forced to partially or totally suspend their activities. When the lockdown ended (decided on May 11, 2020), organizations were able to restart, even if incompletely. In order to understand the issues affecting French NPOs, several networks and federations joined forces to conduct a vast survey of NPOs leaders: the Mouvement associatif, as the main NPOs federation, the Réseau National des Maisons d'Associations, and Recherches \& Solidarités, which brings together experts and academics. They were supported in particular by the Department of Youth, Popular Education and Associative Life of the Ministry of National Education and Youth.

Thanks to the support of these networks and the public authorities, the survey collected 12,248 responses and in particular 1,896 responses from arts and cultural NPOs leaders between May 18 and June 15, 2020. The organizations targeted by this survey are only arts and cultural "associations", as French grassroots volunteer organizations (GVOs). There are 344,300 arts and cultural GVOs in France that represent $23 \%$ of French NPOs (Tchernonog \& Prouteau, 2019). This article does not neglect the importance in France of public cultural and arts organizations or social enterprises in this sector. However, the survey was initiated by federations and public authorities only interested in private NPOs under the law of 1901 defining "associations", in particular because they are the most 
Fig. 1 Resilience framework studied in the present article. Lecture: This framework is based on the researches proposed by (a): Fyffe (2014); b Kim et al. (2020); c Kimberlin et al. (2011) and d Searing et al. (2021). The white arrows indicate links that have been statistically tested by regressions, while the black arrows indicate that the impact of the crisis is also noticeable in the resources available (in particular in the wording of the questions), although no statistical tests have been carried out

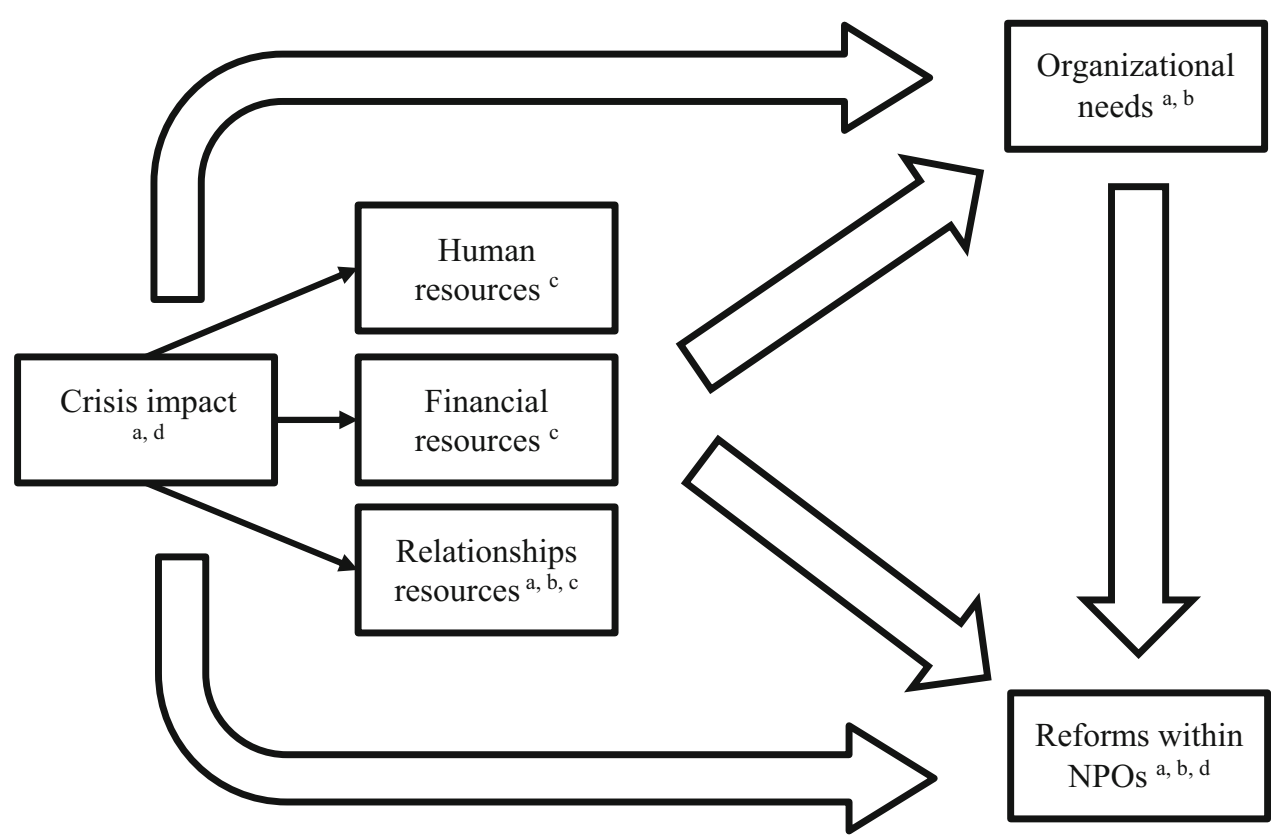

numerous. Henceforth, the use of the term "NPO" refers to these organizations only.

The questions, response methods and dissemination were carried out by all the partners. Thus, our work is a database analysis. Table 1 presents the characteristics of the sample and underlines that these NPOs have few employees, as GVOs. They rely mostly on their volunteers to function (Tchernonog \& Prouteau, 2019). The sample gives more weight to employing NPOs because they are more integrated into federations networks and thus were more easily reached by the survey. The same is true for NPOs with larger budgets: in reality, cultural and arts NPOs in France have modest budgets. However, these slight imbalances compared to the population will help avoid problems with statistical analysis. Finally, the beneficiary public of the NPOs in the sample is generally undifferentiated. Age or vulnerability criteria are sometimes added while some NPOs intervene with other organizations. Thus, the NPOs in the sample are not clubs but open to all.

The obtained data can be grouped into several categories (Table 2). First, based on the three issues outlined in introduction, the NPOs analyzed their strengths and difficulties with regard to human resources (variables 1 to 6 ), in terms of financial resources (variables 7 to 14) and finally about the relational and partnership resources (variables 15 to 18 ). Once this observation was made, the NPOs assessed the crisis impact on their viability (variables 19 to 23, concerning activity, cash flow and governance). Finally, the NPOs expressed their needs (variables 24 to 27), as well as the reforms undertaken during the lockdown (variables 28 to 34 ).

Only the variables related to the crisis impact are ordinal, the others are binary. In order to study the resilience of NPOs, the statistical studies conducted are univariate (Table 2) and multivariate (Tables 4, 5 and 6). Following Mosley et al. (2012), logistic regressions are proposed in accordance with the objectives of this research, i.e., establishing the determinants of the needs expressed as well as the reforms carried out during the lockdown. Two control variables were added: annual budget as well as number of employees. These two variables indicate stable human and financial resources before the crisis occurred. By contrast, variables 1 to 18 deal with the access to resources and the capacity of NPOs to mobilize them. The wording of the questions indicates the effect of the pandemic on such access, but, in accordance with the objectives of this article, the statistical link between the crisis impact and available resources is not tested. Figure 1 shows the tests conducted with the white arrows but also this untested effect with the black arrows.

The correlation matrix (Table 4) shows no statistical problems. The statistical tests conducted for the logistic regressions (Tables 5 and 6) confirm their relevance, as do 
Table 1 Presentation of the sample

\begin{tabular}{|c|c|c|c|c|}
\hline & $\mathrm{N}$ & $\%$ of the sample & $\%$ in arts and cultural NPOs & $\%$ in all French NPOs \\
\hline \multicolumn{5}{|l|}{ Number of employees } \\
\hline 0 & 928 & 48.9 & 87 & 88 \\
\hline 1 or 2 & 445 & 23.5 & $<5: 12$ & $<5: 7.8$ \\
\hline 3 to 5 & 262 & 13.8 & & \\
\hline 6 to 9 & 114 & 6.0 & 5 to $9: 1$ & 5 to $9: 2.1$ \\
\hline 10 to 19 & 122 & 6.4 & $<1$ & 1.7 \\
\hline 20 to 49 & 22 & 1.2 & & \\
\hline More than 50 & 3 & 0.2 & $<1$ & 0.4 \\
\hline \multicolumn{5}{|l|}{ Budget } \\
\hline$<10 \mathrm{k} €$ & 527 & 27.8 & 77.4 & 74.6 \\
\hline $10 \mathrm{k} €-50 \mathrm{k} €$ & 611 & 32.2 & 16.5 & 18.9 \\
\hline $50 \mathrm{k} €-100 \mathrm{k} €$ & 294 & 15.5 & 4.4 & 3.9 \\
\hline $100 \mathrm{k} €-200 \mathrm{k} €$ & 226 & 11.9 & & \\
\hline $200 \mathrm{k} €-500 \mathrm{k} €$ & 145 & 7.6 & 1 & 1.3 \\
\hline $500 \mathrm{k} €-1,000 \mathrm{k} €$ & 48 & 2.5 & 0.6 & 1.3 \\
\hline More than $1,000 \mathrm{k} €$ & 22 & 1.2 & & \\
\hline \multicolumn{5}{|c|}{ Public (Several choices were possible) } \\
\hline All & 1,477 & 77.9 & & \\
\hline Families & 264 & 13.9 & & \\
\hline Children $(<11)$ & 561 & 29.6 & & \\
\hline Adolescents (11-17) & 348 & 18.4 & & \\
\hline Young adults (18-30) & 167 & 8.8 & & \\
\hline Adults & 497 & 26.2 & & \\
\hline Seniors & 203 & 10.7 & & \\
\hline People with disabilities & 165 & 8.7 & & \\
\hline People in great difficulty & 101 & 5.3 & & \\
\hline Ill people & 36 & 1.9 & & \\
\hline Other organizations & 182 & 9.6 & & \\
\hline
\end{tabular}

Source of data in the fourth and fifth columns: Insee, "enquête Situation des associations en 2018", https://www.insee.fr/fr/metadonnees/source/ operation/s1494/presentation, accessed on September 7, 2021, and Tchernonog and Prouteau (2019)

the $\mathrm{R}^{2} \mathrm{~s}$ which vary between 0.15 and 0.51 . The independent variables in Tables 5 and 6 are slightly different since the correlation matrix allowed for a fine selection of variables.

\section{Results}

\section{Descriptive Statistics}

Voluntary human resources have been particularly affected by the crisis and especially by the lockdown. One out of two NPOs saw their partners close down while these partners allowed them to have access to beneficiaries. $31 \%$ of NPOs lost contact with their volunteers and $24 \%$ had to change their missions. Volunteers were too at risk to remain involved in $20 \%$ of organizations while long-distance relationships were complex for $19 \%$.

The main financial problems were related to membership fees: $29 \%$ of NPOs members stopped paying. $16 \%$ of NPOs have lost a part of their income and $15 \%$ are concerned about loss of public orders or corporate funding. $8 \%$ of NPOs lost all their income during the crisis, which is the strongest impact. Other decreases in (public or private) funding and increased costs due to the crisis affected 5 to $10 \%$ of NPOs. 
Table 2 Presentation of the study questions and variables

\begin{tabular}{|c|c|c|c|c|c|c|}
\hline Questions (in italics) and proposed answers & \# & Modalities name & $\mathrm{N}$ & Mean & Median & SD \\
\hline \multicolumn{7}{|l|}{ Human resources in times of crisis } \\
\hline \multicolumn{7}{|c|}{ What challenges have most strongly impacted volunteering in your NPO during the lockdown? (1: yes, 0: no) } \\
\hline A context that has led to changes in volunteer missions & 1 & HR_VM & 1,896 & 0.24 & 0 & 0.43 \\
\hline Loss of contact with some volunteers & 2 & HR_LC & 1,896 & 0.31 & 0 & 0.46 \\
\hline $\begin{array}{l}\text { The difficulties encountered to respect the safety rules (lack of } \\
\text { masks, gloves, hydroalcoholic gel...) }\end{array}$ & 3 & HR_SR & 1,896 & 0.19 & 0 & 0.39 \\
\hline $\begin{array}{l}\text { Technical difficulties and hesitations related to long-distance } \\
\text { relationships }\end{array}$ & 4 & HR_LDR & 1,896 & 0.26 & 0 & 0.44 \\
\hline $\begin{array}{l}\text { The structures with which the NPO was linked were no longer } \\
\text { functioning (school, museum, restaurant, central kitchen, etc.) }\end{array}$ & 5 & HR_CLO & 1,896 & 0.51 & 1 & 0.50 \\
\hline The number of people identified as being particularly at risk & 6 & HR_RV & 1,896 & 0.20 & 0 & 0.40 \\
\hline
\end{tabular}
among volunteers

\section{Financial resources in times of crisis}

If so, which of your NPO's resources and expenses are particularly affected by the crisis? (1: yes, 0: no)

A significant loss of income from activities

A total loss of income from activities, taking into account the mode of intervention of the association and the official instructions

A loss of public subsidies

The risk of cancellation of public orders (contracts, delegation of services)

A decrease in funding from partner foundations

A decrease in funding from corporate partners (e.g. sponsorship etc.)

A decrease in resources from membership fees

An increase in costs generated by crisis-related expenses

\section{Relationships resources in times of crisis}

Today, following these last weeks of lockdown, you would say of the different public and private partnerships of your NPO that: (1: yes, 0: no) They are globally maintained, without change

They have rather strengthened

$\begin{array}{ll}15 & \text { RR_GM } \\ 16 & \text { RR_SG } \\ 17 & \text { RR_ST } \\ 18 & \text { RR_DEV }\end{array}$

Our NPO has developed new partnerships during the crisis

\section{Crisis impact on NPOs}

To summarize the situation of your NPO during this period of lockdown, to what extent did you manage to maintain its activity?

How much do you estimate, approximately, the financial impact of these cancellations for your NPO (cumulative loss of revenue and expenses incurred that have become useless...)?

How many months of operations are covered by your cash flow today?
7 FR_SL

8 FR_TL

9 FR_PS

11 FR_FO

12 FR CP

13 FR_MF

14 FR IC $\begin{array}{llll}1,896 & 0.16 & 0 & 0.36\end{array}$

$\begin{array}{llll}1,896 & 0.08 & 0 & 0.28\end{array}$

$\begin{array}{llll}1,896 & 0.05 & 0 & 0.22\end{array}$

$\begin{array}{llll}1,896 & 0.15 & 0 & 0.36\end{array}$

$\begin{array}{llll}1,896 & 0.05 & 0 & 0.22\end{array}$

$\begin{array}{llll}1,896 & 0.15 & 0 & 0.36\end{array}$

$\begin{array}{llll}1,896 & 0.29 & 0 & 0.46\end{array}$

$\begin{array}{llll}1,896 & 0.09 & 0 & 0.29\end{array}$

\section{3}

\section{4} 50 40

0


Table 2 continued

\begin{tabular}{|c|c|c|c|c|c|c|}
\hline Questions (in italics) and proposed answers & $\#$ & Modalities name & $\mathrm{N}$ & Mean & Median & SD \\
\hline $\begin{array}{l}\text { In projection, to what extent do you expect to execute your } \\
\text { projected } 2020 \text { (or 2019-2020) budget? }\end{array}$ & 22 & $\begin{array}{l}\text { PB-5: }>80 \% \\
\text { PB-4: } 60-80 \% \\
\text { PB-3: } 40-60 \% \\
\text { PB-2: } 20-40 \% \\
\text { PB-1: }<20 \% \\
\text { PB-0: Based on the information } \\
\text { available, a bankruptcy petition } \\
\text { cannot be excluded }\end{array}$ & 1,431 & 3.20 & 3 & 1.35 \\
\hline $\begin{array}{l}\text { Personally, do you feel that during the past period, your } \\
\text { management team (board of directors, Bureau) has functioned: }\end{array}$ & 23 & $\begin{array}{l}\text { GOV-4: Collectively and in a } \\
\text { satisfactory manner } \\
\text { GOV-3: Collectively but with some } \\
\text { difficulties } \\
\text { GOV-2: Only with some of the leaders } \\
\text { GOV-1: I sometimes felt a bit lonely }\end{array}$ & 1,875 & 2.77 & 3 & 1.09 \\
\hline \multicolumn{7}{|l|}{ NPOs' needs } \\
\hline $\begin{array}{l}\text { Have you activated the financial solutions proposed by the public } \\
\text { authorities? (1: yes, } 0: \text { no) } \\
\text { What are your immediate concerns regarding your NPO recover }\end{array}$ & 24 & yes, $0:$ no) & 1,878 & 0.33 & 0 & 0.47 \\
\hline $\begin{array}{l}\text { The need for new volunteers because some will not be able to } \\
\text { restart their activities }\end{array}$ & 25 & ND_NV & 1,896 & 0.10 & 0 & 0.30 \\
\hline $\begin{array}{l}\text { The recovery of the dialogue with the local communities and the } \\
\text { administrations }\end{array}$ & 26 & ND_DA & 1,896 & 0.33 & 0 & 0.47 \\
\hline Confirmation of our financial partnerships (grants, competitions, & 27 & ND_FP & 1,896 & 0.48 & 0 & 0.50 \\
\hline
\end{tabular}
services...)

\section{Reforms within NPOs}

Did this episode of lockdown lead you to rethink, at least in part, the general functioning of your NPO? (1: yes, 0: no)

No, it did not seem necessary

No, due to lack of time and perspective

Yes, we have strengthened our cooperation with other actors in the area (communities, companies, NPOs, etc.)

Yes, we have adapted our relationships with volunteers

Yes, we have adopted new practices and new ways of doing things (organization, governance, etc.)

Yes, we have implemented digital tools to work or keep the link 33 REF_DI at a distance

Yes, we have temporarily redesigned our relationships with our beneficiaries/members

\begin{tabular}{llllll}
28 & REF_NN & 1,896 & 0.23 & 0 & 0.42 \\
29 & REF_NT & 1,896 & 0.17 & 0 & 0.38 \\
30 & REF_CO & 1,896 & 0.06 & 0 & 0.25 \\
& & 1,896 & 0.16 & 0 & 0.36 \\
31 & REF_VL & 1,896 & 0.21 & 0 & 0.41 \\
32 & REF_MA & 1,896 & 0.40 & 0 & 0.49 \\
33 & REF_DI & 1,896 & 0.20 & 0 & 0.40 \\
34 & REF_BF & & & & \\
\hline
\end{tabular}

Partnerships have generally been maintained over time (39\% of NPOs) but few changes have been made: $2 \%$ of NPOs have strengthened these links and $2 \%$ have tried to approach new partners.

The crisis has had a huge impact on the life of arts and cultural NPOs. Activity has collapsed: only about $20 \%$ has been maintained. The cancelled events cost a few thousand euros, which is significant when budgets are usually in this order of magnitude (see Table 1). The cash flow is around 3 months for the majority, and the projected budget is wiped out. This sudden stop has slowed down the planned activities and about $50 \%$ of the budget could be realized. NPOs governance has also suffered, even if the strength of the collective management has remained.

The needs of NPOs are concentrated around financial $(48 \%)$ and public $(33 \%)$ partnerships as well as financial solutions offered by the State and public administrations (33\%). $10 \%$ of NPOs also lack volunteers.

Finally, NPOs took advantage of the lockdown to reform. Only $23 \%$ did not see the value of changing and 


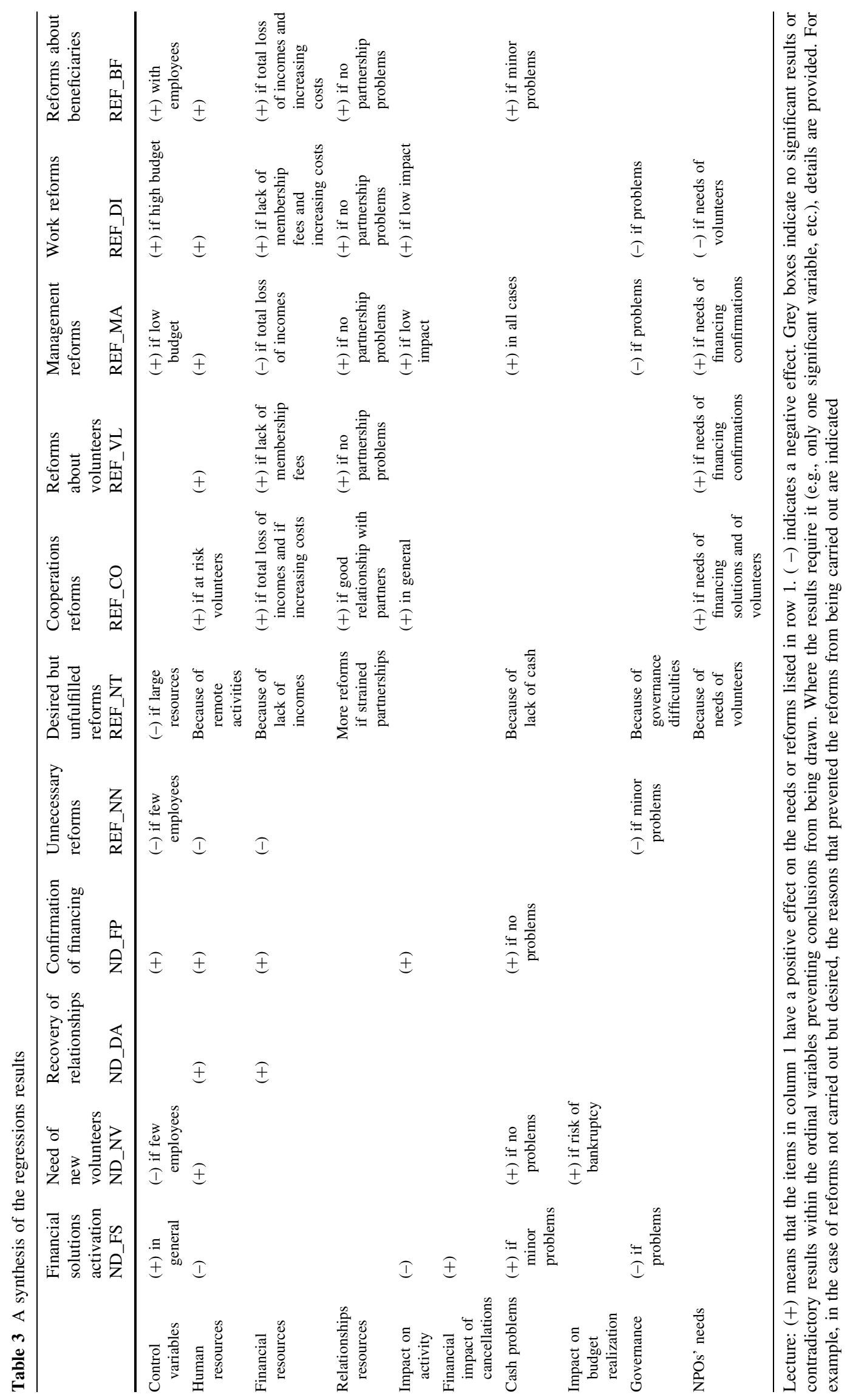


$17 \%$ could not but would have liked to. Thus, $60 \%$ of NPOs have carried out reforms. $40 \%$ have modernized their operations through digitalization. $21 \%$ have changed their management and governance. 20\% have reworked their relationship with beneficiaries and members and $17 \%$ with volunteers. Only $6 \%$ have strengthened their partnerships.

\section{Determinants of NPOs' Needs and Reforms within NPOs}

Table 3 provides a summary of the results of the regressions conducted.

The activation of public financial aid (ND_FS) can be explained in particular by the impact of the crisis on the activity, event cancellations, cash flow problems and governance difficulties. The rather structural problems of human resources do not lead NPOs to seek these financial solutions. In other words, NPOs only called on aid to solve their short-term problems. The presence of employees (and therefore of wages) leads to the use of these aids, as well as large budgets.

The need for new volunteers (ND_NV) is logically due to the problems related to human resources but also because of the financial impact of the crisis. Volunteering becomes the way to save the activity, since the service providers or the employees could not be paid.

Relationships with funders (ND_FP) and partners (ND_DA) are a need for NPOs that have seen their structural situation deteriorate from a human and financial perspective, much more than from the immediate impact of the crisis. Confirmation of financing is particularly crucial for organizations with stable resources, in order to secure their financing in the short and medium term.

Structural problems with resources access are likely to convince NPOs to reform (REF_NN). However, governance must be maintained and NPOs with no or few employees are the most mobilized. When the survival of the organization is at stake, it seems more difficult to launch fundamental reforms. Other barriers have prevented NPOs from reforming (REF_NT), including long-distance relationships, lack of revenue, cash flow and volunteers, and governance failures.

Globally, the reforms undertaken have common key success factors. The difficulties related to human resources, loss of incomes and cost increases push them to rethink themselves in order to obtain new ones. Managerial reforms are an exception: they are slowed down if financial resources are lacking.

If partnerships have not been a problem, NPOs have been able to reform without worrying about their stakeholders. Again, however, the impact on the activity remains crucial: it must not be too strong to allow changes to be undertaken. The same applies to the maintenance of governance arrangements. Finally, state aid and the need for confirmation of funding are driving forces for reform.

\section{Findings}

The discussion of the results resumes the analytical framework proposed. The four subsections answer the research questions by examining the resilience of NPOs based on the impact of the crisis, their access to resources, the needs expressed and finally the reforms undertaken.

\section{Clear Difficulties in NPOs: An Overview of the Crisis Impact}

The obtained results show a catastrophic short-term situation for NPOs in the arts and culture sector. This subsection builds on the descriptive results related to the impact of the crisis (i.e., the first issue presented on the left side of Fig. 1).

The activities are almost at a standstill, and above all, liquidity is also lacking to quickly restart the activity once the administrative measures are partially lifted. Cash flow only covers about 3 months of activity and is problematic: the spring 2020 lockdown lasted 2 months, plus administrative closures that remained numerous until summer 2020 .

Maintaining governance arrangements at an appropriate degree is one of the only positive aspects. Theoretically, governance should protect the identity of the organization (Hoarau \& Laville, 2008) and thus prevent both a few people from flouting collective democracy and the activity from drifting away from missions and values.

\section{Key Resources in Heterogeneous States}

The diagnosis of the resources available to NPOs is less bleak. The discussion here is based on the descriptive statistics for the resources (i.e., the three resources shown on the left side of Fig. 1) and their role in the logistic regressions.

The difficulties are real and multiple, both human and financial. However, the size of the nonprofit sector and its particularities around volunteering are strengths. In other words, the near-stop in activity and the attacks on financial viability could have produced even more severe structural effects. Access to resources could have been more difficult in times of global crisis. In reality, only a minority of NPOs haven't been able to rely on their volunteers and financial partners, following the declarations of NPOs leaders.

Relations with stakeholders, by contrast, are disappointing. Only $40 \%$ of NPOs have seen their partnerships 
maintained (RR_GM) and yet few reforms or efforts have been undertaken by NPOs (see RR_SG, RR_DEV and REF_CO). NPOs belong to a more or less local community of stakeholders. Their social and societal role is therefore major in calmer times. In times of crisis, NPOs could have strengthened their ties with stakeholders in order to maintain this crucial societal role.

In addition, the NPOs' primary mission toward beneficiaries has hardly been maintained (see, for example, the only $20 \%$ that have evolved their relations with their beneficiaries, REF_BF). This finding is described as disappointing because arts and cultural NPOs could have maintained their societal role by continuing to support their community. It's true that NPOs in the arts and cultural sector have less power than those in the health and social sector, for example, in times of a pandemic. Nevertheless, maintaining links, even remotely, has been done by the other sectors (Plaisance, 2021a).

\section{Specific Needs Explained by Human and Financial Resources}

This sub-section addresses the issues indicated on the right side up of Fig. 1, in order to understand the needs of NPOs and their determinants. The regressions show that stable resources (represented by the control variables) are key determinants in order to explain NPOs' specific needs.

The needs expressed by NPOs provide valuable information about the sector. Only one-third of NPOs felt the need to call on the state (ND_FS and ND_DA). The focus is not only on short-term human, material or financial capitals. Social and relational capital (e.g., communicating on funding stability, recovery plans, etc.) seems equally important, especially because cultural and arts NPOs have significant medium-term needs to prepare their activities. The notions of recovery and restoration emphasized by Fyffe (2014) have a different meaning in the world of culture and the arts: community mobilization around culture is as crucial as financial support.

The challenge for NPOs in the sector is not specifically to attract new volunteers (ND_NV) but to keep those already involved. The sector is indeed extremely dependent on its human capital, as shown by its importance in understanding expressed needs. In addition, these NPOs need to be reassured that medium-term financing will be maintained. This can be explained by the way cultural and artistic NPOs are financed and function (in relation with schools, a cyclical functioning by artistic season, etc.).

\section{Reforms for Resilience: Persistence First}

This final sub-section focuses on the bottom right-hand side of Fig. 1, namely the reforms carried out and their antecedents.

The results show that $77 \%$ of arts and culture NPOs are willing or successful in reforming. The reforms actually affect all three of the resources discussed above.

The main action concerns an immediate adaptation to the context around digital tools in order to maintain actions or simply a social link at a distance. In reality, these actions are intended to preserve the human capital of the organization.

Secondly, the interest of NPOs was focused on internal practices. By improving governance and management, organizations seek to achieve an ideal of efficiency in responding to financial problems. It is also a question of getting better in order to satisfy the stakeholders and thus maximize their (financial) support.

Third, developments have focused on relationships with beneficiaries, members and volunteers. Relational resources are at the heart of the arts and cultural sector, as outlined above. They have been poorly developed and mobilized, which explains the importance of the reforms undertaken. These relationships with the community and with stakeholders are crucial to the future and rebound of NPOs (Bonnafous-Boucher et al., 2003) and are a preview of the thriving addressed by Pratt (2015).

The analysis of the content of the reforms thus shows an orientation towards the restoration of key resources. The logistic regressions unsurprisingly show that reforming implies not suffering too much from the crisis and that reforms are guided by the difficulties of access to resources. Stable resources (represented by the control variables) are not specifically protective but rather help to establish the strength of the organizational context in decisions.

In other words, based on the previous subsections and these findings, in the specific case of arts and cultural NPOs, decisions and reforms for resilience have focused on organizational persistence and not on activity continuity. The administrative constraints naturally guided this decision choice, but the findings provide an answer to Searing et al. (2021) in the French particular context.

\section{Conclusion}

This article focuses on the context of the global Covid-19 pandemic. All organizations and countries were affected. Arts and cultural NPOs have not escaped the crisis and are among the most affected because their operations often involve gatherings and activities that do not follow health guidelines. 
The objective was above all to understand if French artistic and cultural NPOs were able to be resilient during this crisis. For this purpose, the analyses were based on a large survey of NPOs after the first French lockdown during the spring of 2020.

The analysis of the resilience of these organizations has been carried out thanks to the combination of four conceptions of resilience. The findings answer to RQ1 and highlight stronger interruptions in activity than in the other sectors, but a correct resilience if the expressed needs and the ability to make immediate decisions to protect themselves are examined. Following Searing et al. (2021), the activity continuity side of resilience is weakened but the persistence side is particularly strong. The processual analysis also helps to answer RQ2: the type of support that NPOs require is a response to expressed needs, actions to try to extinguish the situational determinants that create these needs and help to carry out reforms.

One of the reasons why the reforms were implemented was that this sector has shown fewer economic problems in comparison with health or social NPOs, for instance (Plaisance, 2021a). Recent studies have already noted too that the crisis impact on NPOs has been slightly minimized thanks to the action of private and public partners (Johnson et al., 2020). This reforming effort is in reality a form of organizational learning, which is also part of the resilience of organizations (Burnard \& Bhamra, 2011; Orth \& Schuldis, 2021).

These answers to the research questions generate other insights. Differentiating the immediate impact of the crisis with the capacity of the NPO to mobilize its resources, as proposed by Fyffe (2014), is extremely important, even if the crisis has effects on these same resources. The seemingly contradictory results (e.g. high short-term financial impact but low difficulties in accessing financial resources) are actually a direct indication of the complexity of these NPOs and their resilience (see Darkow, 2019). This complexity is illustrated by Bhaskara and Filimonau's analysis: "the 'right' combination of skills and resources reinforces organizational resilience" (Bhaskara \& Filimonau, 2021, p. 364).

The main theoretical contribution of this study concerns the application of Fyffe (2014), Kim et al. (2020), Kimberlin et al. (2011) and Searing et al. (2021)'s researches to the French case, to arts and cultural NPOs and to the context of the Covid-19 crisis. Moreover, resilience is studied from a processual approach expected by the literature (Ngoc et al., 2021), explaining the antecedents of decisions made to preserve resilience (Rodríguez-Sánchez et al., 2021; Searing et al., 2021). Understanding the formation of NPOs' needs and the factors that slow down or accelerate reforms deepen the literature on the subject (Searing et al., 2021). Finally, the results contrast with the literature that analyzes resilience as the ability to return to pre-crisis equilibrium (e.g. Bhamra et al., 2011). The fragilities of NPOs before the crisis are numerous and have accentuated its effects (Johnson et al., 2020). Finding a new equilibrium and not to return to an already tense situation would therefore be preferable. As pointed out by Witmer and Mellinger (2016), in NPOs, resilience must serve the integrity and viability of NPOs and thus be a strategy to defend their core values and missions and not only financial health.

The practitioner contributions follow from the above and extends the answer to RQ2. The resilience that organizations seek must be embedded in the values of the NPO, the arts and culture sector and the non-profit sector as a whole. In addition, future NPOs facing a crisis can learn from the actual NPOs' reactions to Covid-19 pandemic: for instance, they would strengthen strategies for securing connections with their communities. The societal role of NPOs must be at the forefront and digitalization is becoming essential.

Finally, a contribution concerns the stakeholders of these NPOs and the public authorities. NPOs have been reforming also to satisfy their stakeholders and this is easier to do when NPOs have good relations with them or when it is a matter of getting their support confirmed. Reassuring NPOs about the future (at the operational, financial and relational levels) is thus a priority. The gap between the massive financial support from public authorities and the impressions of NPOs is explained by needs that are actually less financial than moral: intangible capital is just as crucial in the arts and culture sector as financing or human resources. Thus, in order to meet the objective of this article, the support to be provided to NPOs must in fact reinforce their financial viability (thanks to state solutions) but also operational viability by producing a clear discourse on the future of the sector and on future intentions (of collaboration, of financing, of support in kind, of new rules and protocols for opening, etc.).

The different behaviors listed by Horne and Orr (1997) are found here: NPOs need consideration, commitment or a community that communicates with them. These results confirm that resilience seeks to respond to the demands of the environment (Fyffe, 2014; Witmer \& Mellinger, 2016). The problematic of the French arts and cultural sector during the crisis is highlighted by this point: arts and cultural NPOs expect from the authorities, above all, commitments, clear communication and support, not funding under perfusion. Pratt (2015) had already emphasized the importance of community-based prosperity for the cultural sector.

This work presents a series of limitations. The database specified the questions, variables and response modalities. These were closed questionnaires with no verbatim 
responses and only binary or ordinal responses. Moreover, this analysis of a national case would deserve to be compared with other countries and other sectors. Studies of NPOs financial data would allow for the measurement of resilience to be adjusted beyond the declarative statements of leaders. Finally, this survey focuses on French NPOs, which are specific grassroots volunteer organizations, and not on private for-profit or public arts and cultural organizations.

The concept of resilience can also be studied in a dynamic way (Ma et al., 2018). Thus, based on the state of resilience of French NPOs studied here, a first avenue of research would be to differentiate temporal frames, between short term, mid-term and long-term resilience capacity. Beyond the decisions made during the lockdown, the consequences of the reforms put in place could then be studied. Finally, in order to capture the complexity of crises, NPOs and the whole concept of resilience, the differentiation between small and large risks would be better developed.

\section{Appendix}

See Tables 4, 5, 6 . 


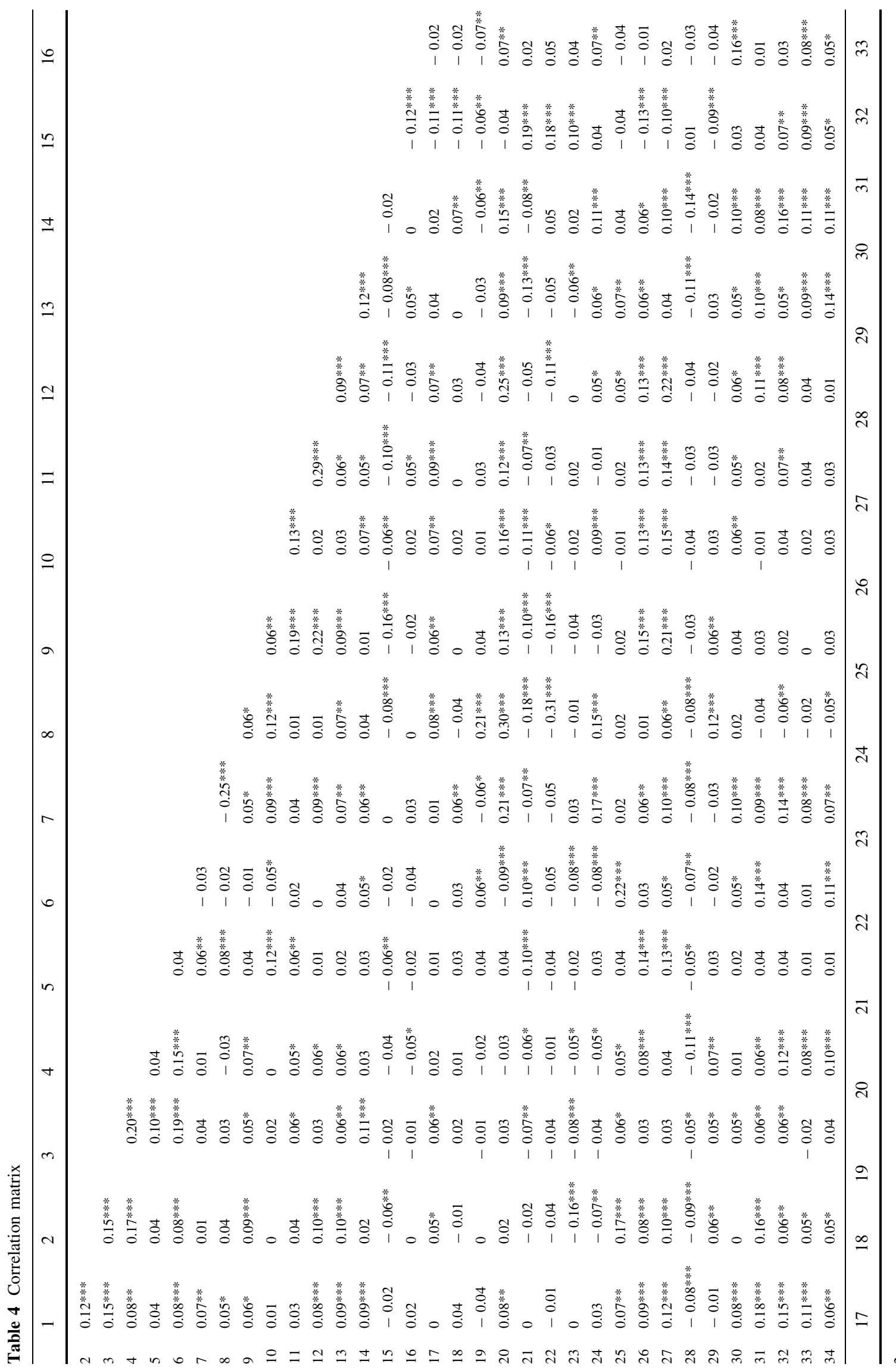




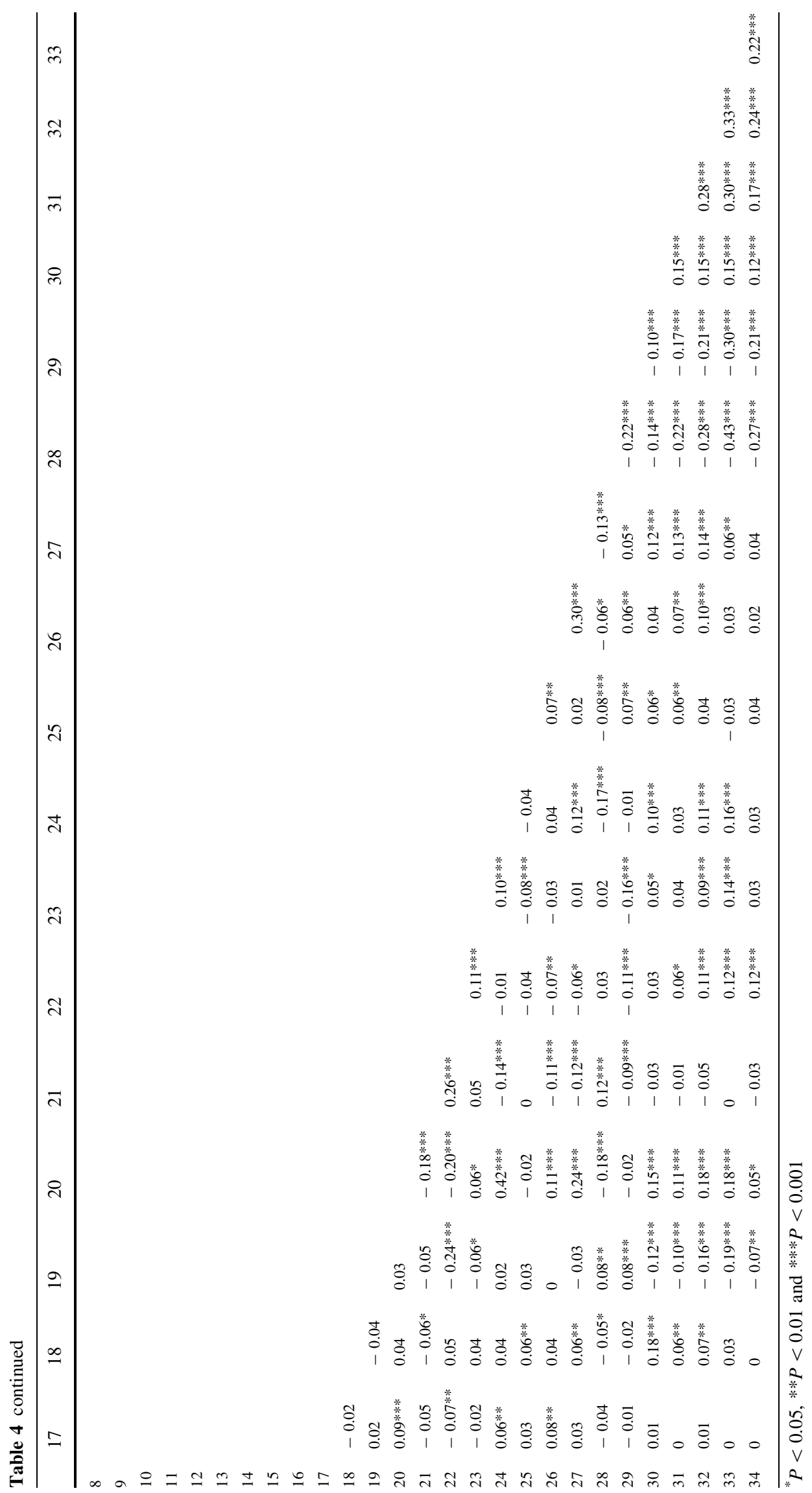




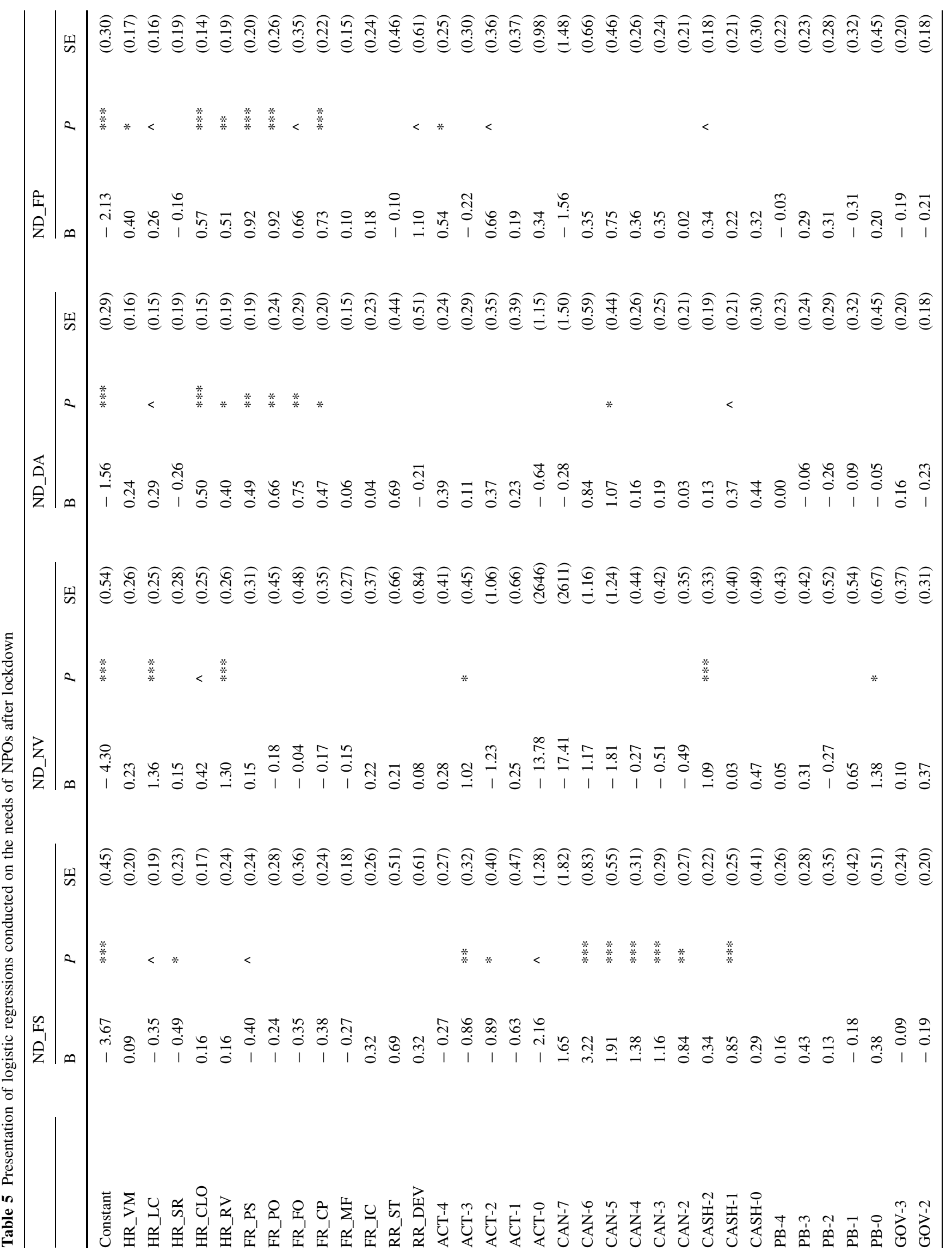




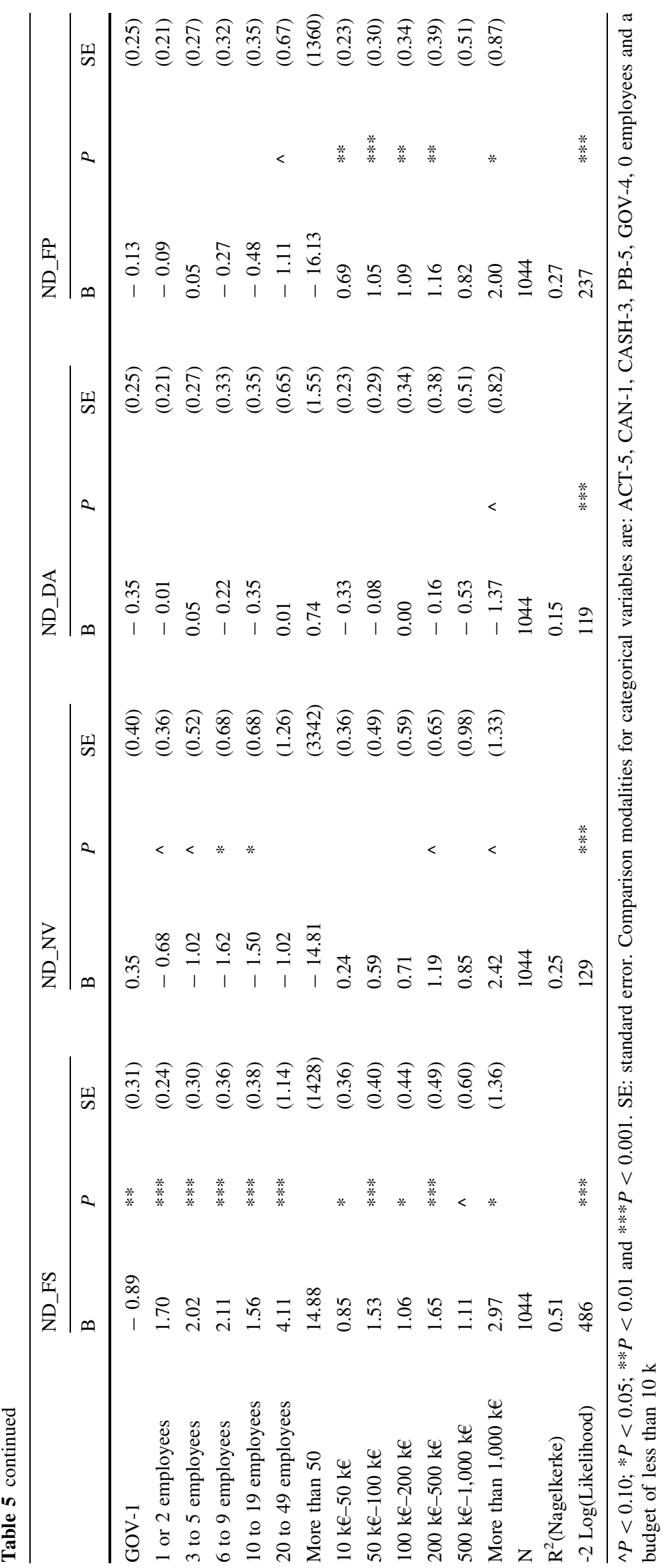




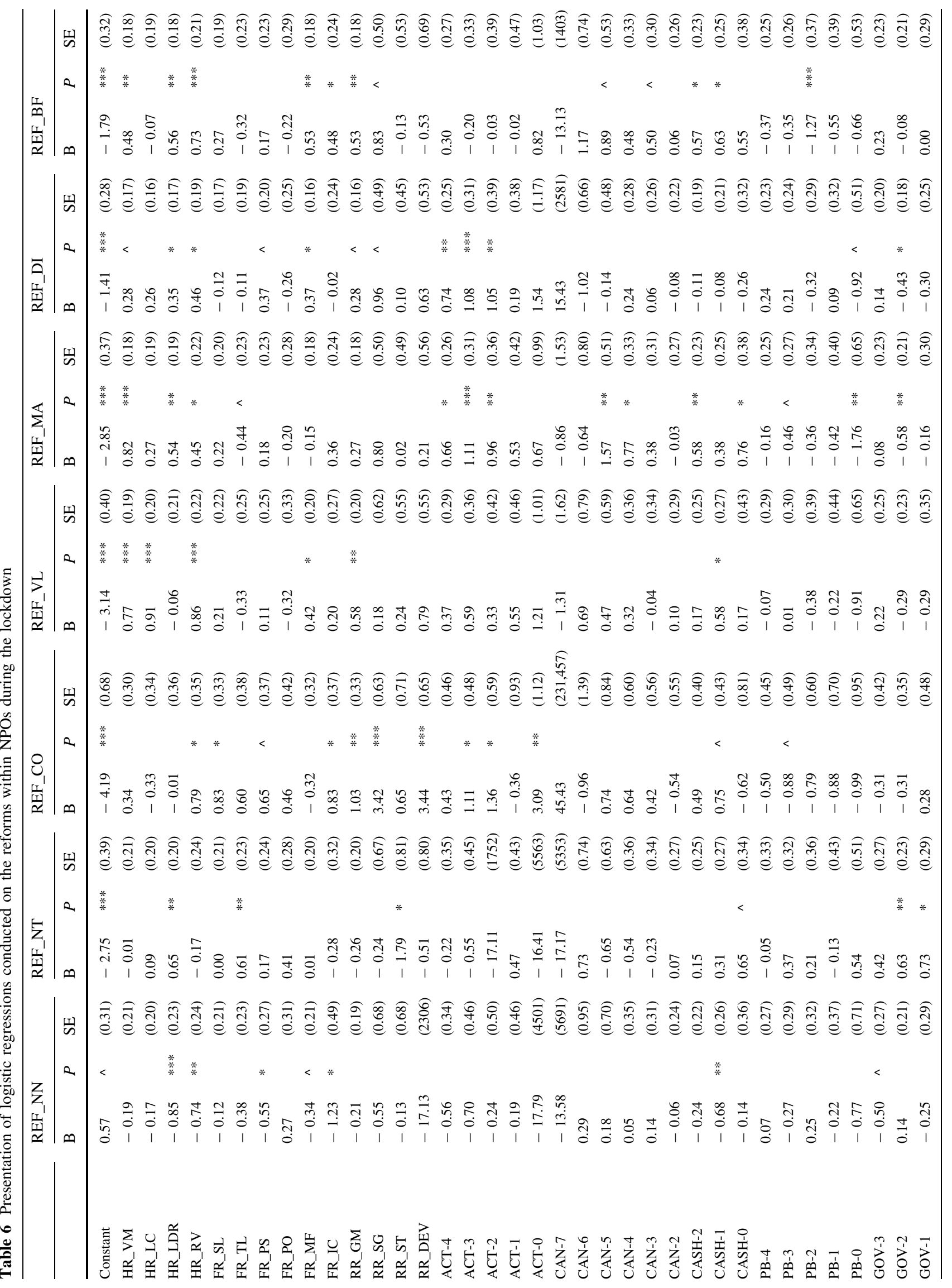




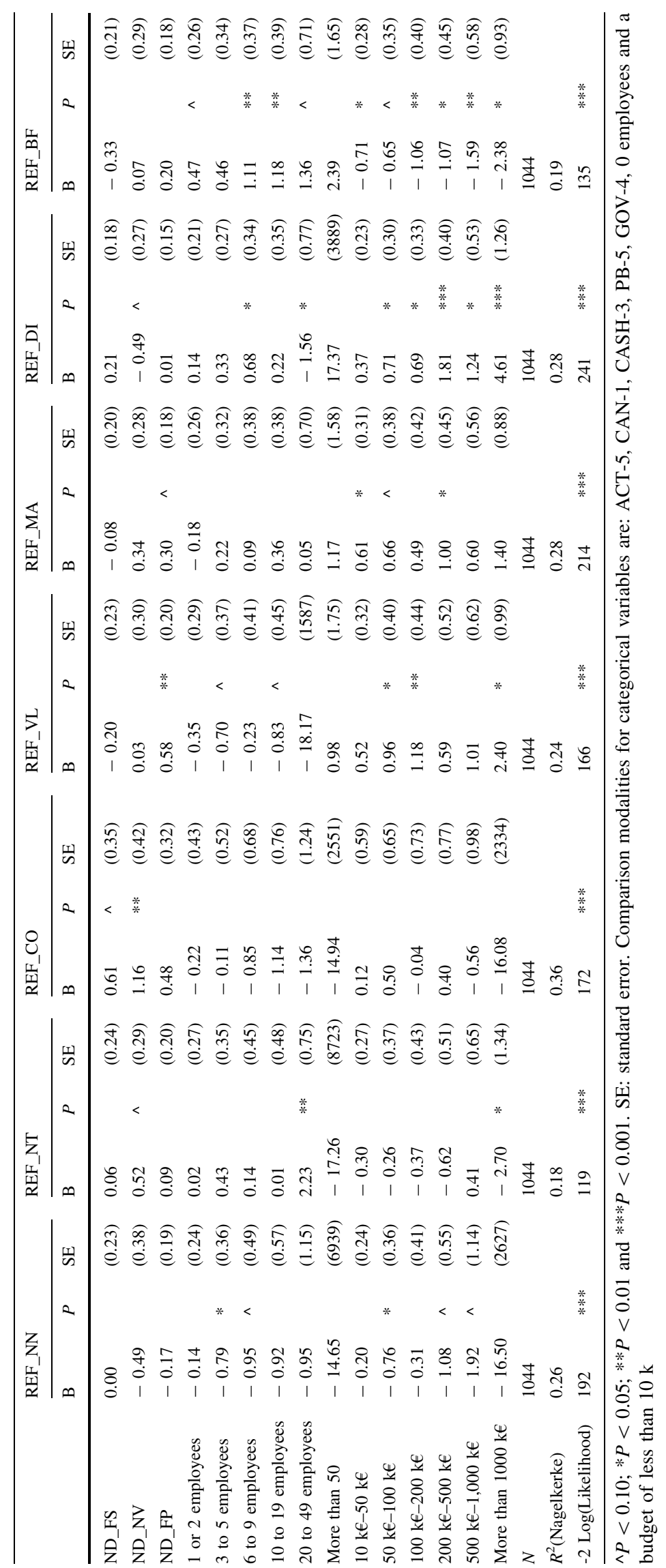


Acknowledgements The author wishes to thank Jacques Malet, Cécile Bazin and Marie Duros of Recherches \& Solidarités for their kind provision of the Covid-19 survey database and their support in the research process undertaken on the basis of this survey.

Funding No funding was received for conducting this study.

Data Availability The data that support the findings of this study are available from Recherches \& Solidarités.

\section{Declarations}

Conflict of interest The author is a board member and a member of the expert committee of Recherches \& Solidarités, and receives no compensation.

Informed Consent Respondents in the data have freely chosen to answer the questionnaire online. All data are stored without any identifying information.

Ethical Approval All procedures performed in studies involving human participants were in accordance with the ethical standards of the institutional and/or national research committee and with the 1964 Helsinki Declaration and its later amendments or comparable ethical standards.

\section{References}

Akingbola, K. (2020). COVID-19: The prospects for nonprofit human resource management. Canadian Journal of Nonprofit and Social Economy Research, 11(1), 16-20. https://doi.org/10.29173/ cjnser.2020v11n1a372

Al-Ayed, S. I. (2019). The impact of strategic human resource management on organizational resilience: An empirical study on hospitals. Business Theory and Practice, 20, 179-186. https:// doi.org/10.3846/btp.2019.17

Betzler, D., Loots, E., Prokůpek, M., Marques, L., \& Grafenauer, P. (2020). COVID-19 and the arts and cultural sectors: Investigating countries' contextual factors and early policy measures. International Journal of Cultural Policy. https://doi.org/10.1080/ 10286632.2020 .1842383

Bhamra, R., Dani, S., \& Burnard, K. (2011). Resilience: The concept, a literature review and future directions. International Journal of Production Research, 49(18), 5375-5393. https://doi.org/10. 1080/00207543.2011.563826

Bhaskara, G. I., \& Filimonau, V. (2021). The COVID-19 pandemic and organisational learning for disaster planning and management: A perspective of tourism businesses from a destination prone to consecutive disasters. Journal of Hospitality and Tourism Management, 46, 364-375. https://doi.org/10.1016/j. jhtm.2021.01.011

Bonnafous-Boucher, M., Chatelain-Ponroy, S., Evrard, Y., \& Mazallon, F. (2003). Quel avenir pour les théâtres lyriques? Revue Francaise De Gestion, 142(1), 169-188.

Bourlès, L., and Nicolas, Y. (2021). Impact de la crise sanitaire sur l'évolution des chiffres d'affaires enregistrés dans le champ de la culture (Note de conjoncture No. 2021-1). Ministère de la Culture.

Burnard, K., \& Bhamra, R. (2011). Organisational resilience: Development of a conceptual framework for organisational responses. International Journal of Production Research, 49(18), 5581-5599. https://doi.org/10.1080/00207543.2011. 563827
Chen, R., Xie, Y., \& Liu, Y. (2021). Defining, conceptualizing, and measuring organizational resilience: A multiple case study. Sustainability, 13(5), 2517. https://doi.org/10.3390/su13052517

Chen, X. (2021). Nonprofit financial resilience: Recovery from natural disasters. VOLUNTAS International Journal of Voluntary and Nonprofit Organizations, 32(5), 1009-1026. https://doi.org/ 10.1007/s11266-021-00415-w

Darkow, P. M. (2019). Beyond "bouncing back": Towards an integral, capability-based understanding of organizational resilience. Journal of Contingencies and Crisis Management, 27(2), 145-156. https://doi.org/10.1111/1468-5973.12246

Duchek, S. (2014). Growth in the face of crisis: The role of organizational resilience capabilities. Academy of Management Proceedings, 2014(1), 13487. https://doi.org/10.5465/ambpp. 2014.225

Duchek, S. (2020). Organizational resilience: A capability-based conceptualization. Business Research, 13(1), 215-246. https:// doi.org/10.1007/s40685-019-0085-7

Finchum-Mason, E., Husted, K., \& Suárez, D. (2020). Philanthropic foundation responses to COVID-19. Nonprofit and Voluntary Sector Quarterly, 49(6), 1129-1141. https://doi.org/10.1177/ 0899764020966047

Fyffe, S. D. (2014). An exploration of resilient nonprofit organizations: How human services providers in virginia survived and thrived the great recession of 2007-2009. Virginia Polytechnic Institute and State University.

Green, E., Ritchie, F., Bradley, P., \& Parry, G. (2021). Financial resilience, income dependence and organisational survival in UK charities. VOLUNTAS International Journal of Voluntary and Nonprofit Organizations, 32(5), 992-1008. https://doi.org/10. 1007/s11266-020-00311-9

Hillmann, J., \& Guenther, E. (2021). Organizational resilience: A valuable construct for management research? International Journal of Management Reviews, 23(1), 7-44. https://doi.org/ 10.1111/ijmr.12239

Hoarau, C., and Laville, J.-L. (2008). La gouvernance des associations: économie, sociologie, gestion. Ramonville Saint-Agne: Erès.

Horne, J. F., \& Orr, J. E. (1997). Assessing behaviors that create resilient organizations. Employment Relations Today, 24(4), 29-39. https://doi.org/10.1002/ert.3910240405

Johnson, A. F., Rauhaus, B. M., \& Webb-Farley, K. (2020). The COVID-19 pandemic: A challenge for US nonprofits' financial stability. Journal of Public Budgeting, Accounting \& Financial Management, 29(6), 33-46. https://doi.org/10.1108/JPBAFM06-2020-0076

Kim, K., Andrew, S. A., \& Jung, K. (2020). Building resilient organizations: Organizational resilience as a network outcome. International Journal of Public Administration. https://doi.org/ 10.1080/01900692.2020.1758720

Kim, M., \& Mason, D. P. (2020). Are you ready: Financial management, operating reserves, and the immediate impact of COVID-19 on nonprofits. Nonprofit and Voluntary Sector Quarterly, 49(6), 1191-1209. https://doi.org/10.1177/ 0899764020964584

Kimberlin, S., Schwartz, S., \& Austin, M. (2011). Growth and resilience of pioneering nonprofit human service organizations: A cross-case analysis of organizational histories. Journal of Evidence-Based Social Work, 8(1), 4-28. https://doi.org/10. 1080/15433710903272820

Kober, R., \& Thambar, P. J. (2021). Coping with COVID-19: The role of accounting in shaping charities' financial resilience. Accounting, Auditing \& Accountability Journal, 34(6), 1416-1429. https://doi.org/10.1108/AAAJ-09-2020-4919

Lengnick-Hall, C. A., Beck, T. E., \& Lengnick-Hall, M. L. (2011). Developing a capacity for organizational resilience through 
strategic human resource management. Human Resource Management Review, 21(3), 243-255. https://doi.org/10.1016/j.hrmr. 2010.07.001

Linnenluecke, M. K. (2017). Resilience in business and management research: A review of influential publications and a research agenda. International Journal of Management Reviews, 19(1), 4-30. https://doi.org/10.1111/ijmr.12076

Littlewood, D., \& Holt, D. (2018). Social enterprise resilience in subSaharan Africa. BUSINESS STRATEGY \& DEVELOPMENT, 1(1), 53-63. https://doi.org/10.1002/bsd2.11

Liu, Y., \& Yin, J. (2020). Stakeholder relationships and organizational resilience. Management and Organization Review, 16(5), 986-990. https://doi.org/10.1017/mor.2020.58

Lloyd-Smith, M. (2020). The COVID-19 pandemic: Resilient organisational response to a low-chance, high-impact event. $B M J$ Leader, 4(3), 109-112. https://doi.org/10.1136/leader-2020000245

Ma, Z., Xiao, L., \& Yin, J. (2018). Toward a dynamic model of organizational resilience. Nankai Business Review International, 9(3), 246-263. https://doi.org/10.1108/NBRI-07-2017-0041

Mano, R. (2010). Organizational crisis, adaptation, and innovation in Israel's nonprofit organizations: A learning approach. Administration in Social Work, 34(4), 344-350. https://doi.org/10.1080/ 03643107.2010.500985

McMullin, C., \& Raggo, P. (2020). Leadership and governance in times of crisis: A balancing act for nonprofit boards. Nonprofit and Voluntary Sector Quarterly, 49(6), 1182-1190. https://doi. org/10.1177/0899764020964582

Moran, K. A. (2016). Organizational resilience: Sustained institutional effectiveness among smaller, private, non-profit US higher education institutions experiencing organizational decline. Work, 54(2), 267-281. https://doi.org/10.3233/WOR-162299

Mosley, J. E., Maronick, M. P., \& Katz, H. (2012). How organizational characteristics affect the adaptive tactics used by human service nonprofit managers confronting financial uncertainty. Nonprofit Management and Leadership, 22(3), 281-303. https:// doi.org/10.1002/nml.20055

Ngoc, S. D., Luc, T. D., Thi, H. H. M., Nguyen, H. H. T., \& O'Mahony, B. (2021). Enhancing resilience in the Covid-19 crisis: Lessons from human resource management practices in Vietnam. Current Issues in Tourism. https://doi.org/10.1080/ 13683500.2020.1863930

Orth, D., \& Schuldis, P. M. (2021). Organizational learning and unlearning capabilities for resilience during COVID-19. The Learning Organization, 28(6), 509-522. https://doi.org/10.1108/ TLO-07-2020-0130.

Ovans, A. (2015). What resilience means, and why it matters. Harvard Business Review, 4, 71.

Paarlberg, L. E., LePere-Schloop, M., Walk, M., Ai, J., \& Ming, Y. (2020). Activating community resilience: The emergence of COVID-19 funds across the United States. Nonprofit and Voluntary Sector Quarterly, 49(6), 1119-1128. https://doi.org/ $10.1177 / 0899764020968155$
Pearson, C. M., \& Clair, J. A. (1998). Reframing crisis management. Academy of Management Review, 23(1), 59-76. https://doi.org/ 10.5465/amr.1998.192960

Plaisance, G. (2021). French nonprofit organizations facing COVID19 and lockdown: Maintaining a sociopolitical role in spite of the crisis of resource dependency. Canadian Journal of Nonprofit and Social Economy Research, 12(S1), 65-81.

Plaisance, G. (2021b). Les associations françaises face à la crise de la Covid-19: Une approche par les ressources et les parties prenantes. Management international/International Management/Gestion Internacional (OnlineFirst).

Pratt, A. C. (2015). Resilience, locality and the cultural economy. City, Culture and Society, 6(3), 61-67. https://doi.org/10.1016/j. ccs.2014.11.001

Rodríguez-Sánchez, A., Guinot, J., Chiva, R., \& López-Cabrales, Á. (2021). How to emerge stronger: Antecedents and consequences of organizational resilience. Journal of Management \& Organization, 27(3), 442-459. https://doi.org/10.1017/jmo.2019.5

Sabatino, M. (2016). Economic crisis and resilience: Resilient capacity and competitiveness of the enterprises. Journal of Business Research, 69(5), 1924-1927. https://doi.org/10.1016/j. jbusres.2015.10.081

Sawalha, I. H. S. (2015). Managing adversity: Understanding some dimensions of organizational resilience. Management Research Review, 38(4), 346-366. https://doi.org/10.1108/MRR-01-20140010

Searing, E. A. M., Wiley, K. K., \& Young, S. L. (2021). Resiliency tactics during financial crisis: The nonprofit resiliency framework. Nonprofit Management and Leadership, Early View (Online Version of Record before inclusion in an issue). https://doi.org/10.1002/nml.21478

Tchernonog, V., \& Prouteau, L. (2019). Le paysage associatif français: mesures et évolutions. Dalloz.

Valero, J. N., Jung, K., \& Andrew, S. A. (2015). Does transformational leadership build resilient public and nonprofit organizations? Disaster Prevention and Management, 24(1), 4-20. https://doi.org/10.1108/DPM-04-2014-0060

Visser, W. (2020). Measuring future resilience: A multilevel index. Corporate Governance The International Journal of Business in Society, 21(2), 252-267. https://doi.org/10.1108/CG-01-20200044

Vogus, T. J., \& Sutcliffe, K. M. (2007). Organizational resilience: Towards a theory and research agenda. In 2007 IEEE International Conference on Systems, Man and Cybernetics (pp. 3418-3422). Presented at the 2007 IEEE International Conference on Systems, Man and Cybernetics. https://doi.org/10.1109/ ICSMC.2007.4414160

Witmer, H., \& Mellinger, M. S. (2016). Organizational resilience: Nonprofit organizations' response to change. Work, 54(2), 255-265. https://doi.org/10.3233/WOR-162303

Publisher's Note Springer Nature remains neutral with regard to jurisdictional claims in published maps and institutional affiliations. 